\title{
NASA Satellite Monitoring of Water Clarity in Mobile Bay for Nutrient Criteria Development
}

Slawomir Blonski,, Kara Holekamp,, and Bruce A. Spiering **

${ }^{*}$ Science Systems and Applications, Inc.

${ }^{* *}$ NASA Applied Science and Technology Project Office

Stennis Space Center, Mississippi 


\section{Background}

- Water quality standards in the U.S. consist of:

- designated uses (the services that a water body provides; e.g., drinking water, aquatic life, harvestable species, recreation)

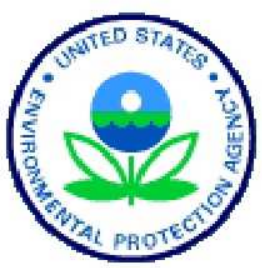

- criteria that define the environmental conditions that must be maintained to support the uses

- For estuaries and coastal waters in the Gulf of Mexico, there are no numeric (quantitative) criteria to protect designated uses from effects of nutrients,

- This is largely due to the absence of adequate data that would quantitatively link biological conditions to nutrient concentrations

- Nutrient enrichment in estuaries and coastal waters can be quantified based on response variables that measure phytoplankton biomass and water clarity

- Long-term, spatially and temporally resolved measurements of chlorophyll a concentration, total concentration of suspended solids, and water clarity are needed to establish reference conditions and to quantify stressor-response relationships 


\section{Study Area}

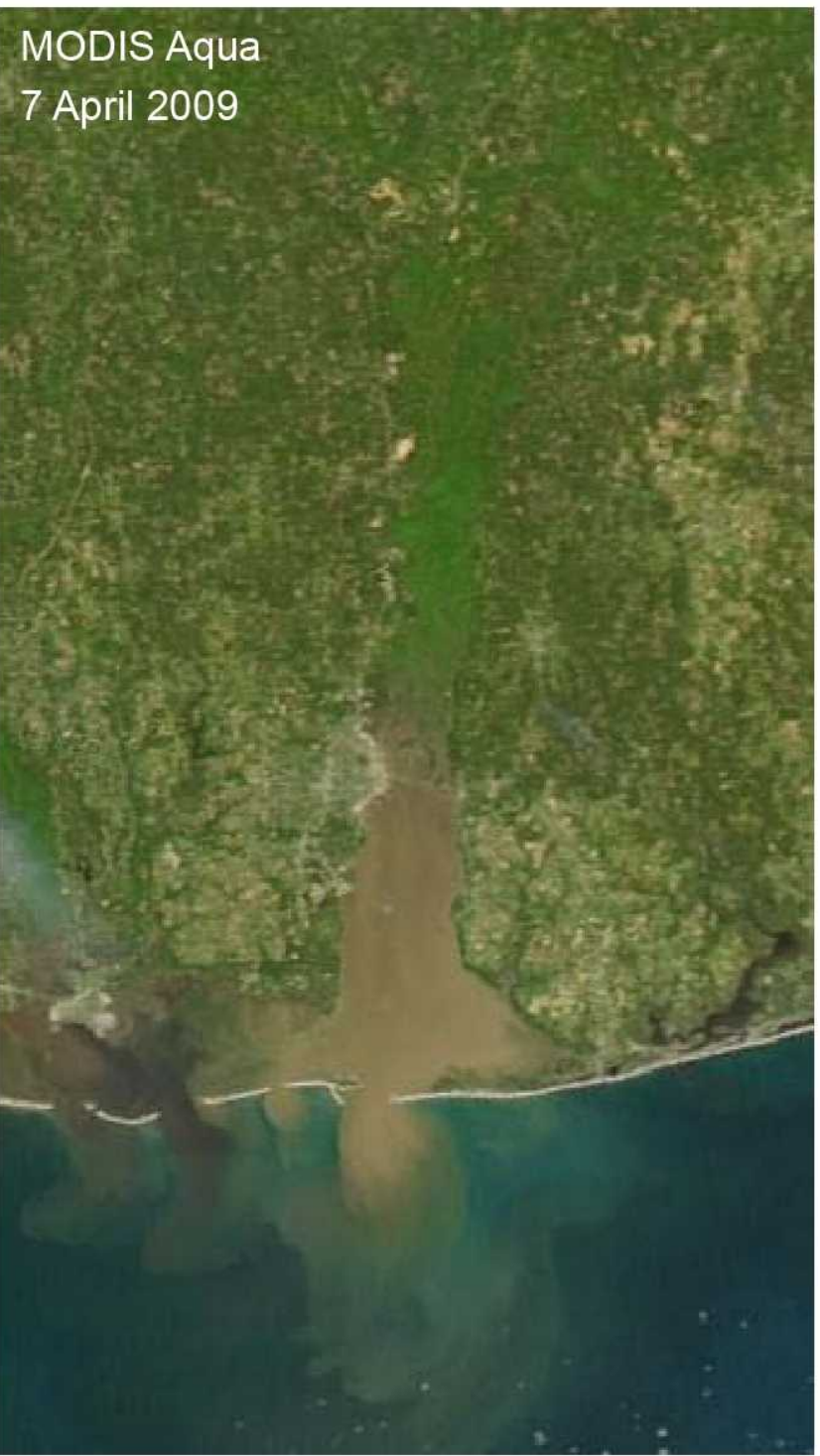

Mobile Bay

- Large, shallow estuary in the north central Gulf of Mexico

- 1000 km² area

- $\sim 3 \mathrm{~m}$ average depth

- Affected by a river inflow from a vast drainage basin that delivers fresh water, suspended sediments, and nutrients

- Due to the shallow nature of the bay and the dynamic climate conditions, re-suspension of accumulated sediments occurs frequently 


\section{Satellite Observations}

- MODIS (Moderate Resolution Imaging Spectroradiometer)

- 2 instruments deployed on different NASA Earth Observing System satellites:

- Terra, launched in December 1999, 10:30 AM sun-synchronous orbit (descending)

- Aqua, launched in May 2002, 1:30 PM sun-synchronous orbit (ascending)

- 36 spectral bands: 20 reflective solar bands with wavelengths from $0.41-2.2 \mu \mathrm{m}$ and 16 thermal emissive bands with wavelengths from 3.7-14.4 $\mu \mathrm{m}$

- 3 spatial resolutions (GSD at nadir):

- $250 \mathrm{~m}$ (2 reflective bands: 600-900 $\mathrm{nm}$ )

- $500 \mathrm{~m}$ (5 reflective bands: $450-2,200 \mathrm{~nm}$ )

- $1 \mathrm{~km}$ (13 reflective bands: 410-1,400 nm)

- extensive calibration efforts to continuously maintain data product quality and to enable creation and analysis of multi-year time series of atmospheric, terrestrial, and ocean measurements
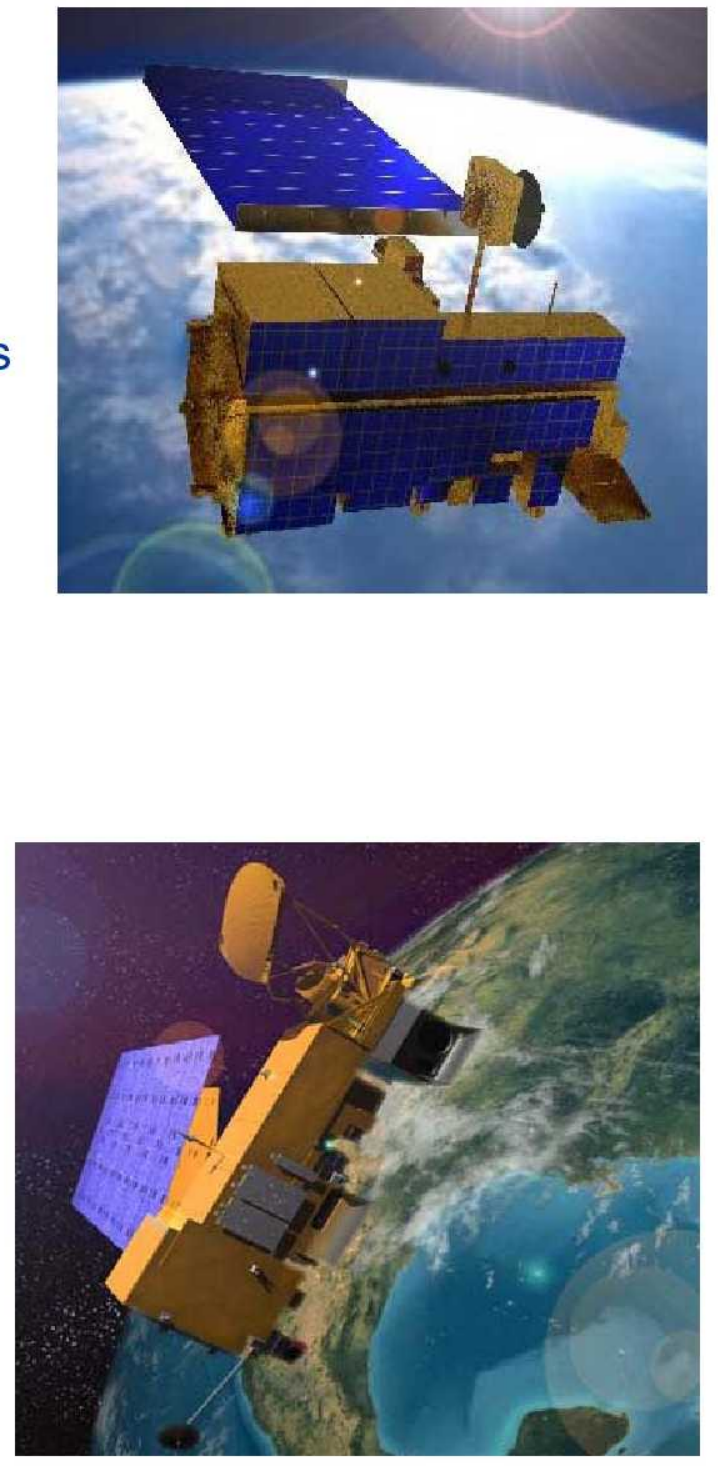


\section{Processing Methods}

- Water clarity defined as light attenuation due to absorption and scattering by water and its suspended or dissolved constituents:

- chlorophyll a (in phytoplankton)

- total suspended solids (TSS), including suspended sediments and phytoplankton

- colored dissolved organic matter (CDOM)

- Time series of water clarity parameters created from the Level 1B MODIS data products obtained from the MODIS Adaptive Data Processing System/Level 1 and Atmosphere Archive and Distribution System (MODAPS/LAADS)

- The Level 1B calibrated radiance products processed using the SeaDAS software to apply atmospheric correction (based on SWIR and NIR bands) and to retrieve inherent optical properties (IOPs) of coastal ocean and estuarine waters

- The following IOPs used to produce water clarity parameters were calculated using the Quasi-Analytical Algorithm:

- total absorption coefficient at $488 \mathrm{~nm}, \mathrm{a}(488)$

- total backscattering coefficients at $488 \mathrm{~nm}$ and $555 \mathrm{~nm}, b_{\mathrm{b}}(488)$ and $b_{\mathrm{b}}(555)$

- phytoplankton absorption coefficient at $443 \mathrm{~nm}, a_{\text {ph }}(443)$

- gelbstoff + detritus absorption coefficient at $412 \mathrm{~nm}, a_{\mathrm{dg}}(412)$ 


\section{Retrieval Algorithms}

- Diffuse attenuation coefficient for the photosynthetically active radiation

- Z.-P. Lee, A. Weidemann, J. Kindle, R.A. Arnone, K.L. Carder, and C. Davis, "Euphotic zone depth: Its derivation and implication to ocean-color remote sensing," J. Geophys. Res. (Oceans), vol. 112, p. 3009 , March 2007

$$
\begin{array}{ll}
K_{\mathrm{d}}(\mathrm{PAR}, z)=K_{1}+\frac{K_{2}}{\sqrt{1+z}} & K_{\mathrm{d}}(\mathrm{PAR}, 0)=K_{1}+K_{2} \\
& K_{1} \text { and } K_{2} \text { calculated from } a(488) \text { and } b_{b}(488)
\end{array}
$$

- Total concentration of suspended solids

- R.W. Gould, R.H. Stavn, M.S. Twardowski, and G.M. Lamela, "Partitioning optical properties into organic and inorganic components from ocean color imagery," Proc. Ocean Optics XVI, Santa Fe, NM, 2002

$$
\text { TSS }=1.58153 \frac{\mathrm{g}}{\mathrm{m}^{2}} \cdot b(555) \quad b(555)=50 b_{\mathrm{b}}(555) \quad \text { or } \quad b(555)=100 b_{\mathrm{b}}(555)
$$

- Chlorophyll a concentration

- A. Bricaud, M. Babin, A. Morel, and H. Claustre, "Variability in the chlorophyll-specific absorption coefficients of natural phytoplankton: Analysis and parameterization," J. Geophys. Res., vol. 100, pp. 13321-13332, July 1995

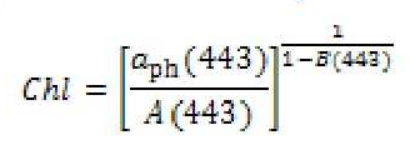

- $\quad$ Light attenuation by CDOM (and detritus)

- Z.-P. Lee, K.L. Carder, and R.A. Arnone, "Deriving inherent optical properties from water color: A multiband quasi-analytical algorithm for optically deep waters," Appl. Opt., vol. 41, pp. 5755-5772, 2002

$$
a_{\mathrm{dg} g}(412)
$$




\section{Point Measurements}
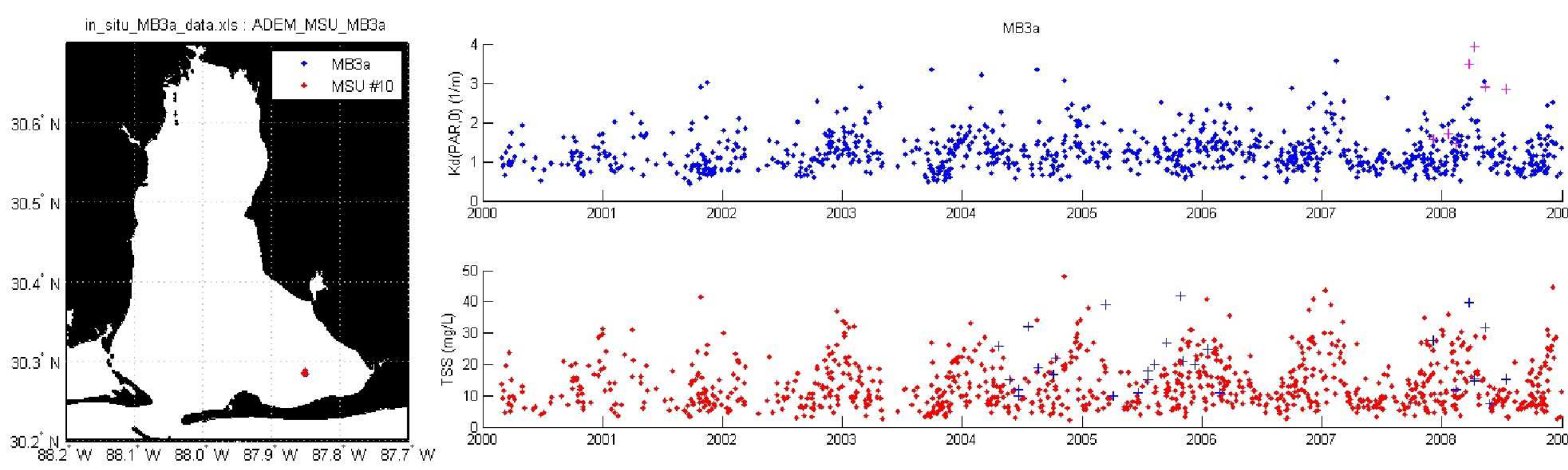

- Above: Location of the ADEM monitoring station MB3a in Bon Secour Bay

- Right: (") Time series of water clarity parameters retrieved from MODIS data for the MB3a station location; (+) MB3a surface monitoring data collected by ADEM in 2004-2006 and MSU in 2007-2008
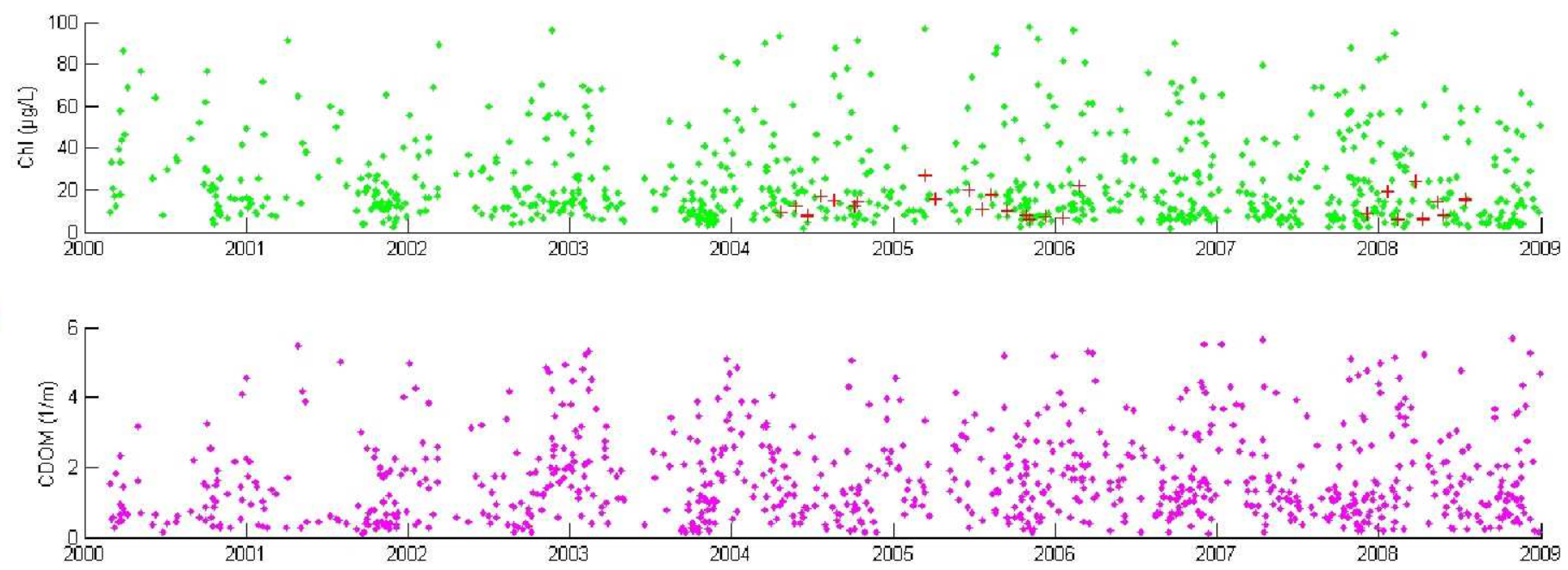


\section{Area Measurements}

Mobile Bay : Bon Secour Bay

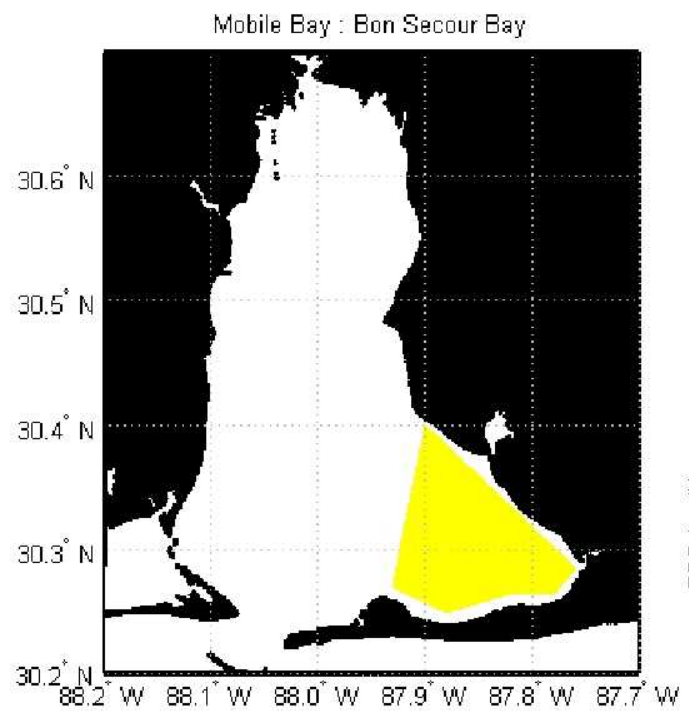

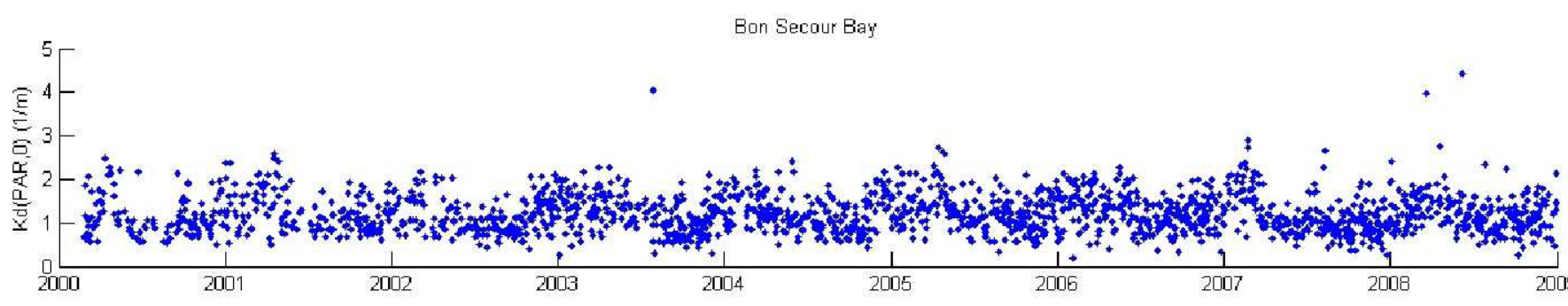

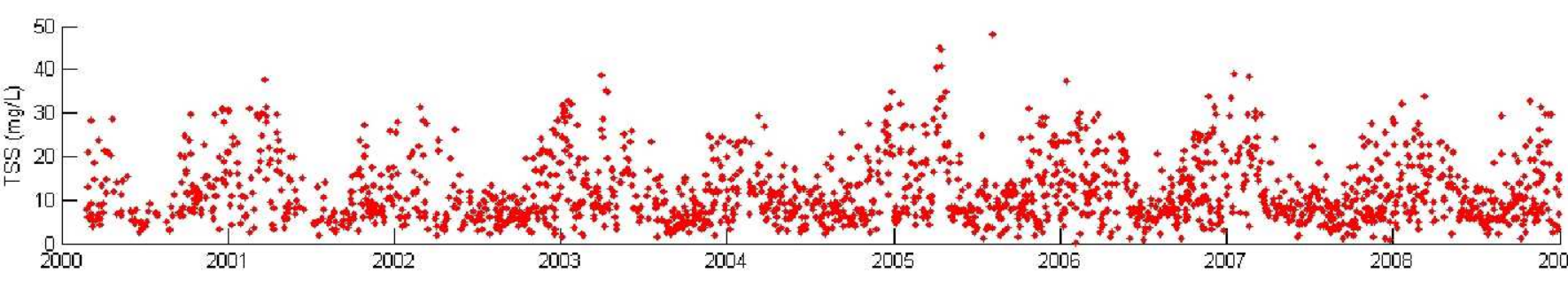

- Above: Location of the Bon Secour Bay area in Mobile Bay

- Right: Time series of water clarity parameters retrieved from MODIS data and aggregated over the Bon Secour Bay area

- No significant long-term trend in water clarity parameters is apparent in

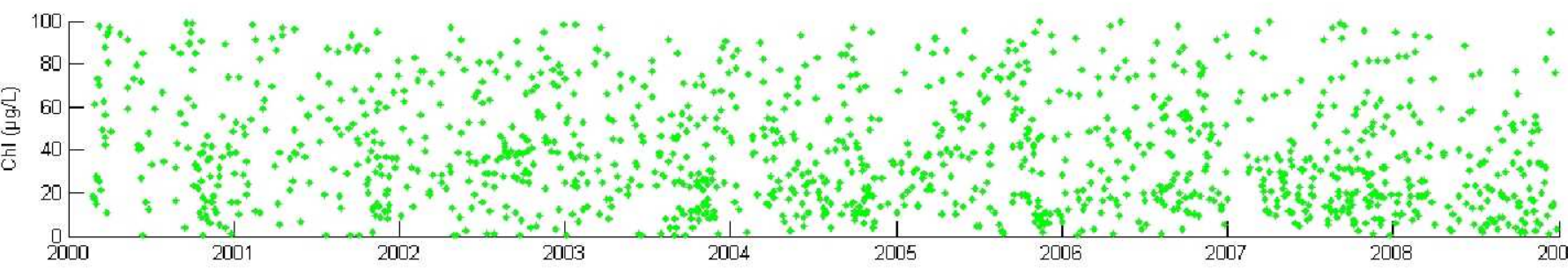
the time period $2000-2008$

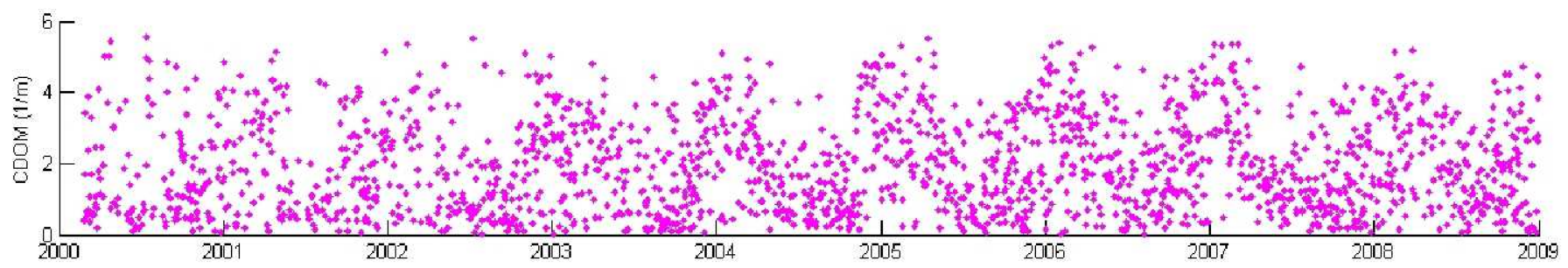




\section{Monthly Statistics}

- Monthly statistics of area-aggregated data for Bon Secour Bay shown as compact box plots with median, $25^{\text {th }}$ and $75^{\text {th }}$ percentiles, full data range, and outliers

- Seasonal trends are emphasized in monthly averages of observations, especially in TSS and CDOM

- Water clarity (light attenuation, $K_{\mathrm{d}}$ ) typically varies by a factor of two between the winter and summer months
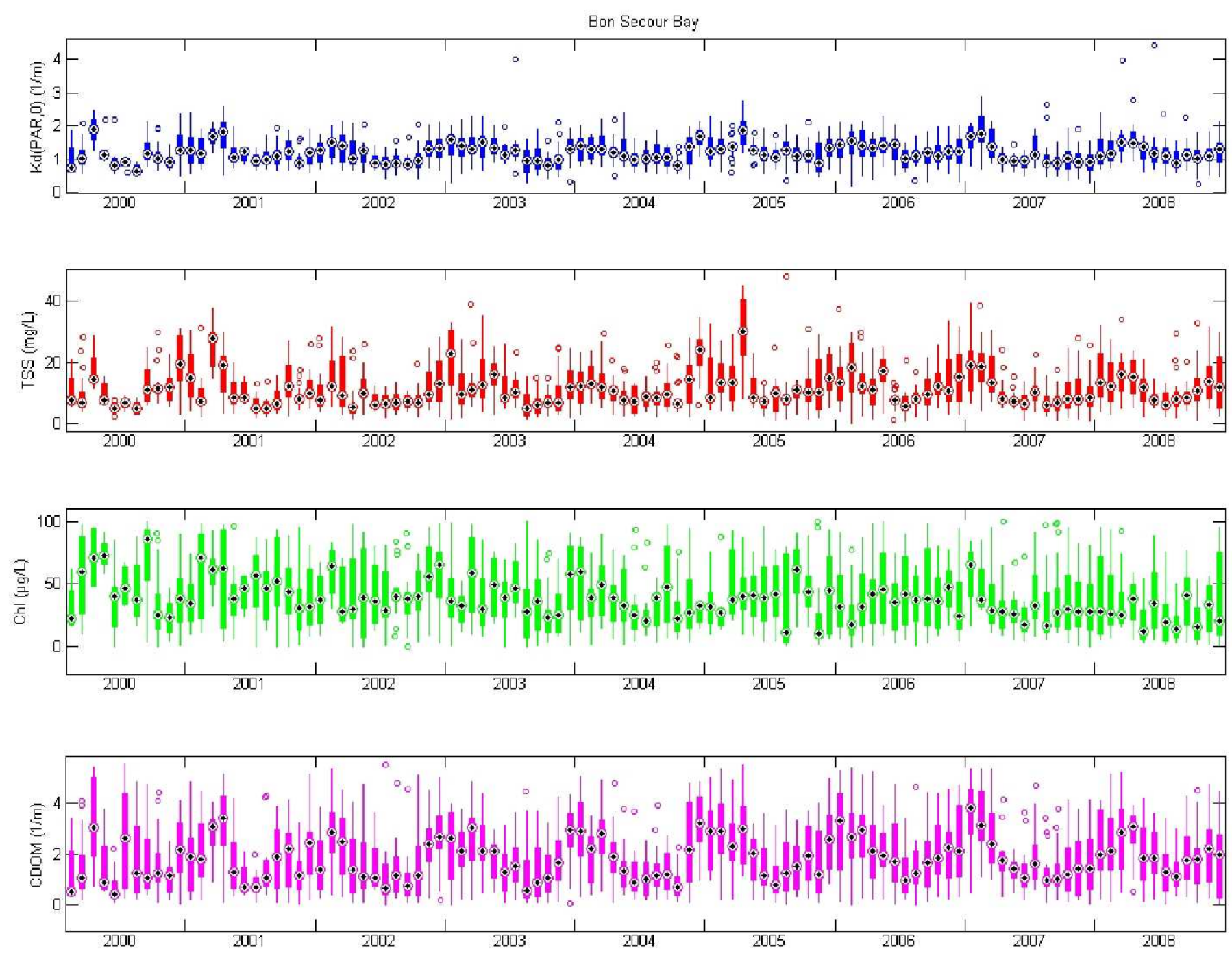


\section{Algorithm Adjustment}

- Scattering to backscattering ratio is treated as an empirical parameter that can be adjusted to undetermined local conditions (such as particle size distribution)

- TSS concentration retrieved with the ratio equal to 100 displays a better agreement with the in situ data than when the ratio equals 50

- Values retrieved from MODIS measurements with the ratio of 50 underestimate TSS concentrations observed in Mobile Bay
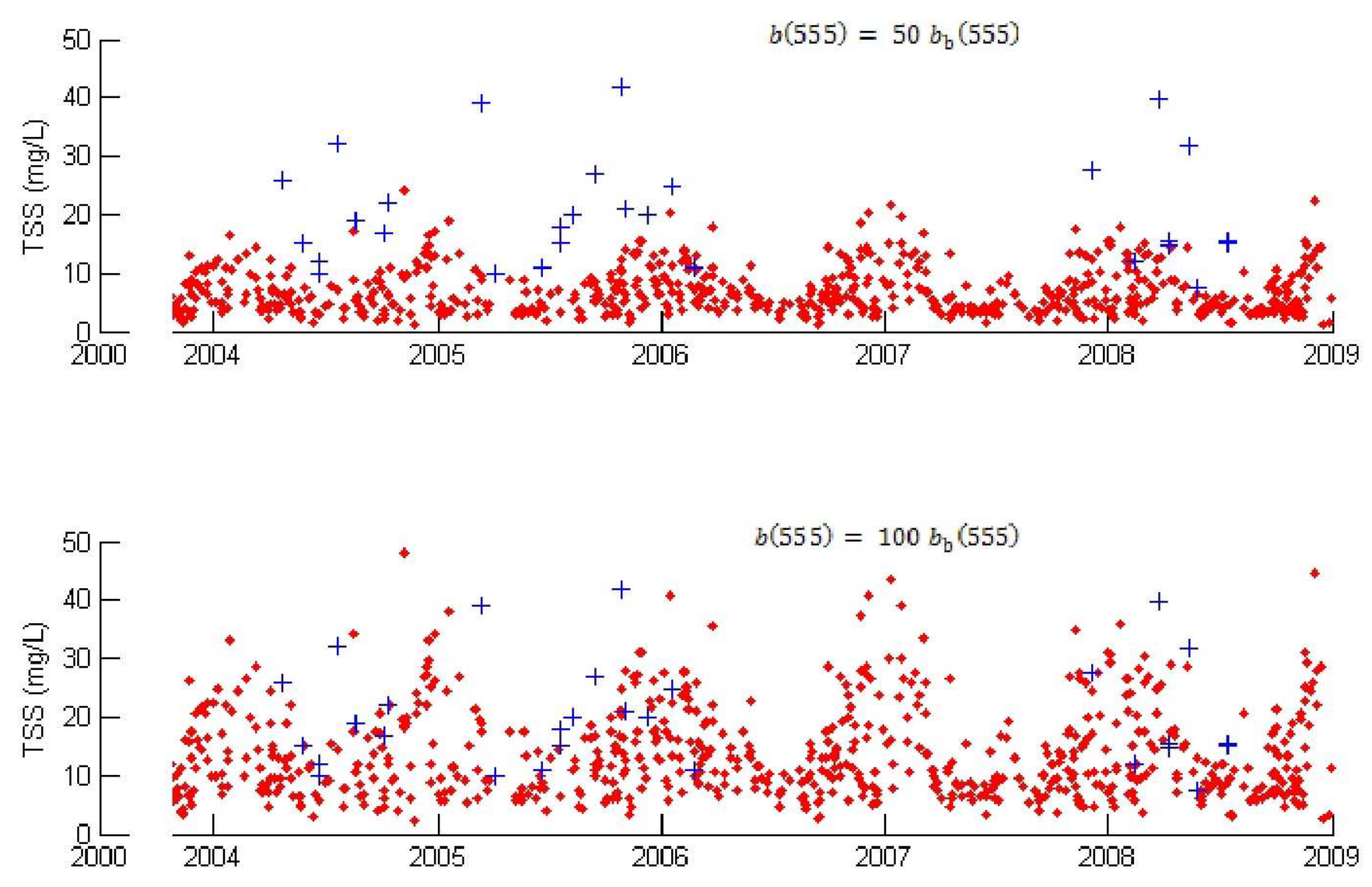


\section{Conclusions}

- This project has demonstrated feasibility of deriving from MODIS daily measurements time series of water clarity parameters that provide coverage of a specific location or an area of interest for $30-50 \%$ of days

- Time series derived for estuarine and coastal waters display much higher variability than time series of ecological parameters (such as vegetation indices) derived for land areas

- Temporal filtering often applied in terrestrial studies cannot be used effectively in ocean color processing

- IOP-based algorithms for retrieval of diffuse light attenuation coefficient and TSS concentration perform well for the Mobile Bay environment: only a minor adjustment was needed in the TSS algorithm, despite generally recognized dependence of such algorithms on local conditions

- The current IOP-based algorithm for retrieval of chlorophyll a concentration has not performed as well: a more reliable algorithm is needed that may be based on IOPs at additional wavelengths or on remote sensing reflectance from multiple spectral bands

- CDOM algorithm also needs improvement to provide better separation between effects of gilvin (gelbstoff) and detritus

- Identification or development of such algorithm requires more data from in situ measurements of CDOM concentration in Gulf of Mexico coastal waters (ongoing collaboration with the EPA Gulf Ecology Division) 


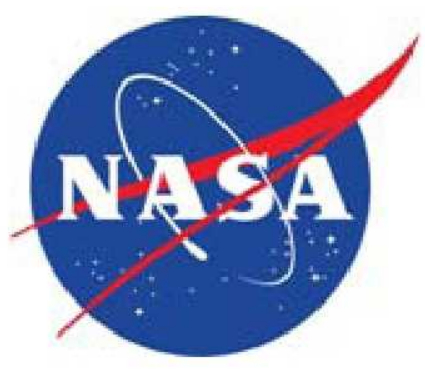

Participation in this work by Science Systems and Applications, Inc., was supported by NASA at the John C. Stennis Space Center, Mississippi, under Task Order NNS04AB54T. 